\title{
Co-relation between Shafting Vibration Performances and Shafting Mechanics Characters in Large Ships
}

\author{
Wen Xiaofei ${ }^{1,2, a^{*}}$, Zhou Ruiping ${ }^{1, b}$, Yuan Qiang ${ }^{1,2, c}$, Hu Xianming ${ }^{3, d}$ \\ ${ }^{1}$ School of Energy and Power Engineering, Wuhan University of Technology,Wuhan, Hubei \\ 430063, China \\ ${ }^{2}$ School of Shipping, Port \& Civil Engineering, Zhejiang Ocean University,Zhoushan, Zhejiang, \\ 316022, China \\ ${ }^{3}$ School of Marine Engineering, Zhejiang International Maritime College,Zhoushan, Zhejiang, \\ 316021, China

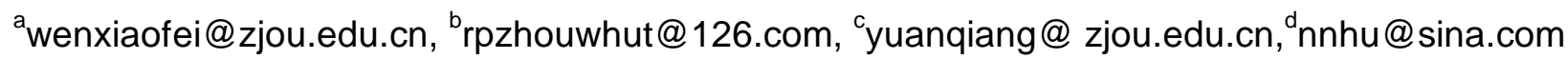

\begin{abstract}
Keywords: marine shafting; shafting vibration; Mechanics characters; vibration performances; co-relation theory

Abstracts: Ship shafting mechanical characteristics reflected the ship shaft system static and dynamic mechanics characteristics, through the ship shafting alignment through theoretical analysis and calculation of ship shafting vibration characteristic includes shafting torsional vibration, transversal and longitudinal vibration characteristics, etc. In this paper, through theoretical and experimental analysis method of combining the research of shafting mechanical characteristics and the influence of the relationship between shafting vibration, theoretical analysis method is applied to analyze the changes on static mechanics characteristics of ship shaft, the test method for research of ship shafting torsional vibration and longitudinal vibration characteristics, and the bearing load and the shafting vibration characteristic frequency and the amplitude as a characteristic, analytical mechanics characteristics change on the influence of shafting vibration characteristics. Finally, summarized some preliminary conclusion, influence law for ship shafting in researchers to provide the reference to the theory, method and train of thought.
\end{abstract}

\section{Introduction}

Marine shafting is one of the key elements of power transmission in marine propulsion system, and its working condition will directly affect the performance and safety of a ship. The static and dynamical mechanics characters of the marine shafting are the internal factors affecting marine propulsion system, meanwhile the vibration performances of shafting become the key parameters for evaluating the dynamic state of the system. Therefore, the study of the relationship between mechanics characteristics and vibration feature has become one of the important researches of ship propulsion system. At home and abroad, the study of marine shafting mechanics is mainly focused on two aspects: marine shaft alignment calculation and verification. Actually, the key study point of marine shafting vibration lies in numerical calculation and a lot of work, such as torsional vibration and its influence factors[1-3], longitudinal vibration reducing and dynamic absorbers [4-5], the characteristics of shafting transversal vibration [6], modal analysis of whirling vibration [7], dynamical characteristics of the low speed rotor and gyroscopic effect theory [8 ], has been done. In a few articles, some shafting vibration tests, like longitudinal vibration test rig of shafting[9-10] and real ship test study[11-12] are introduced. In this paper, the study of the influence of marine shafting mechanics characteristics to marine shafting vibration characteristics is carried out and tries to establish their co-relation.

\section{Principle Ship Parameters}

To meet the study requirements, two types of typical large bulk carriers with different shafting structure are chosen as the research objects, one ship type equipped with single stern-tube bearing and the other equipped with double stern-tube bearing. The principle parameters of the two types of ships 
are showed in Table 1. From which, we can see the main dimensions, the propeller diameters and main engine diesel configuration of the two ship types are the same, only a little differences existing in the value of some items.

Table 1 Principle Ship Parameters

\begin{tabular}{lll}
\hline \multirow{2}{*}{ Items } & $\begin{array}{l}\text { Ship with Single } \\
\text { Stern-tube Bearing }\end{array}$ & $\begin{array}{l}\text { Ship with Double } \\
\text { Stern-tube Bearing }\end{array}$ \\
\hline Length O.A.(m) & 199.9 & 199.9 \\
Breadth MLD(m) & 32.26 & 32.26 \\
Depth MLD(m) & 18.50 & 18.50 \\
Design Draft(m) & 11.30 & 11.30 \\
Engine Type & 5 S60ME-C8.2 & 5 S60ME-C8.2 \\
Nominal Power(kW) & 8050 & 8548 \\
Nominal Speed(r/min) & 89 & 94.5 \\
Propeller Diameter(mm) & 6700 & 6700 \\
Propeller Shaft Diameter(mm) & 510 & 585 \\
Intermediate Shaft Diameter(mm) & 430 & 400 \\
\hline
\end{tabular}

\section{Marine Shafting Type}

To large ships, the engine room is generally located in the stern structure of a ship, called as a stern engine ship. Therefore, the shorter shafting is needed in them. Fore the sake of the length, the shafting arrangement usually consists of a stern-tube bearing and an intermediate bearing. And the stern-tube bearing normally includes an aft stern-tube bearing and fore stern-tube bearing. According to the stern-tube bearing structure and number, the shafting falls into two types: shafting with double stern-tube bearing (Shown in Figure 1) and shafting with single stern-tube bearing (Shown in Figure 2).

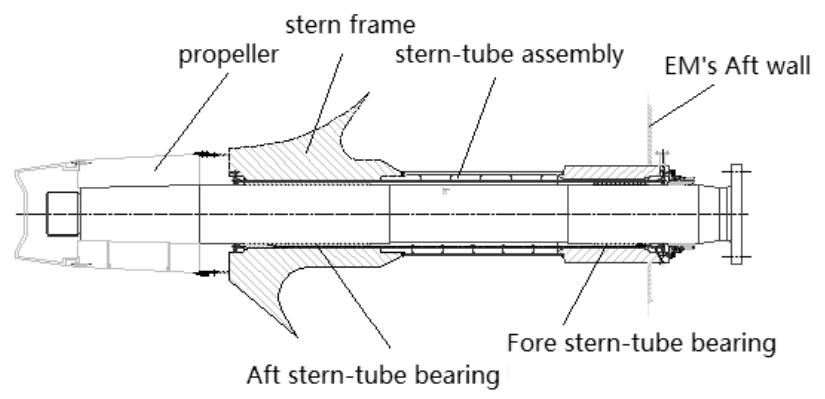

Figure 1 Schematic Diagram of Shafting with Double Stern-tube Bearing

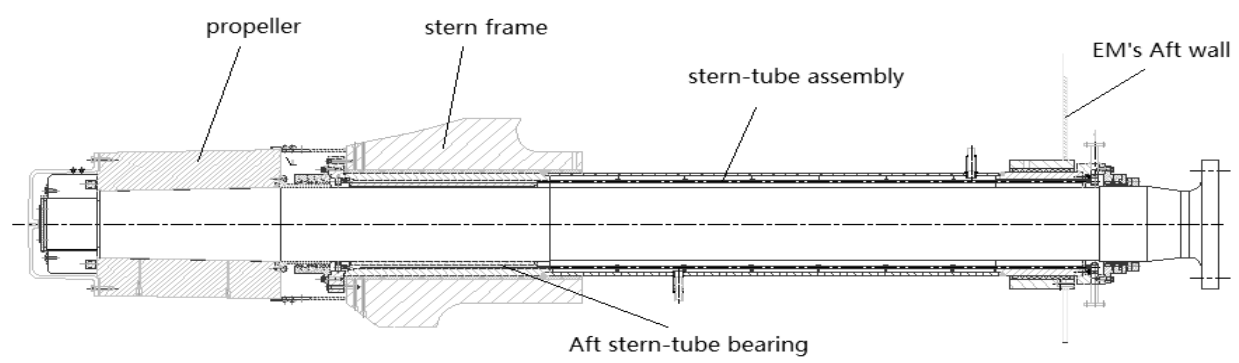

Figure 2 Schematic Diagram of Shafting with Single Stern-tube Bearing

It is a priority to choose the shafting with double stern-tube bearing in ship design and building. If the distance between the stern-tube bearing and the intermediate bearing is enough short, the shafting with single stern-tube bearing will be used in some ship.

\section{Mechanics Characters Of Shafting}

In the calculation of shafting mechanics, three moment equation is often used, and the method of bearing load is adopted to measure and evaluate the mechanical characters. In the article, the finite element method is applied to building the model, simulating and post-procession, and then the loads of 
marine shafting bearings are gotten, shown in the Table2. According to the data of table 2, loads of most bearings in shafting with single stern-tube bearing are significantly higher than those in shafting with double stern-tube bearing. Especially in the cold condition, the loads of aft stern-tube bearing rise more than $17.21 \%$. In the warm condition, the loads rise up to $19.14 \%$. While the load of intermediate bearing reduces by $16.73 \%$ in the cold condition, it increases by $15.77 \%$. At the same time, for the single stern-tube bearing the load of aft stern-tube bearing in the cold condition is higher than that in the warm condition. On the contrary, the load of aft stern-tube bearing in the shafting with double stern-tube bearing in the warm condition is less than the load in the cold condition. So the operating and the propulsion system security are better in the ship with a shafting equipped with double stern-tube bearing.

Table2 Loads of Shafting's Bearings (100\% immersed \& operating)

\begin{tabular}{|c|c|c|c|c|c|c|}
\hline \multirow[b]{2}{*}{ Items } & \multicolumn{3}{|c|}{ Shafting with Single Stern-tube Bearing } & \multicolumn{3}{|c|}{ Shafting with Double Stern-tube Bearing } \\
\hline & $\begin{array}{l}\text { Position } \\
\text { (mm) }\end{array}$ & $\begin{array}{l}\text { Pressure in } \\
\text { Cold (bar) }\end{array}$ & $\begin{array}{l}\text { Pressure in } \\
\text { Warm (bar) }\end{array}$ & $\begin{array}{l}\text { Position } \\
\text { (mm) }\end{array}$ & $\begin{array}{l}\text { Pressure in } \\
\text { Cold (bar) }\end{array}$ & $\begin{array}{l}\text { Pressure in } \\
\text { Warm (bar) }\end{array}$ \\
\hline$A S T B$ & 2042 & 4.70 & 4.73 & 2296 & 4.01 & 3.97 \\
\hline FSTB & / & / & / & 5706 & 1.87 & 2.21 \\
\hline$I S B$ & 7715 & 4.53 & 4.11 & 9263 & 5.44 & 3.55 \\
\hline $\begin{array}{l}\text { M/E B } \\
\text { No.1 }\end{array}$ & 13827 & 1.71 & 2.28 & 13735 & 0.39 & 1.37 \\
\hline $\begin{array}{l}\text { M/E B } \\
\text { No. } 2\end{array}$ & 14685 & 2.45 & 2.01 & 14593 & 2.63 & 1.84 \\
\hline $\begin{array}{l}\text { M/E B } \\
\text { No.3 }\end{array}$ & 15705 & 7.68 & 7.69 & 15613 & 4.09 & 4.12 \\
\hline $\begin{array}{l}\text { M/E B } \\
\text { No.4 }\end{array}$ & 16725 & 7.17 & 7.17 & 16633 & 3.80 & 3.79 \\
\hline $\begin{array}{l}\text { M/E B } \\
\text { No.5 }\end{array}$ & 17745 & 8.91 & 8.91 & 17653 & 4.83 & 4.83 \\
\hline $\begin{array}{l}\text { M/E B } \\
\text { No.6 }\end{array}$ & 18765 & 5.19 & 5.19 & 18673 & 2.74 & 2.74 \\
\hline
\end{tabular}

Ship shafting influence coefficient of the bearing is shown in Table 3. For the single stern bearing shafting, the load changing trend of intermediate bearing and stern tube bearing is contrary; while for the double tail shaft, the load changing trend is consistent. Double bearing shafting influence coefficient is greater than that of the single tail shaft, thus it can be concluded that the shafting with double stern-tube bearing has higher sensitivity to the displacement change, especially when the propulsion system is in the dynamic condition.

Table 3 Influence Coefficient (100\% Immersed \& Warm)

\begin{tabular}{|c|c|c|c|c|c|c|}
\hline \multirow[b]{2}{*}{ Items } & \multicolumn{3}{|c|}{ Ship with Single Stern-tube Bearing } & \multicolumn{3}{|c|}{ Ship with Double Stern-tube Bearing } \\
\hline & $\begin{array}{c}\boldsymbol{A S T B} \\
(\mathrm{N} / \mathrm{mm})\end{array}$ & $\begin{array}{c}\boldsymbol{F S T \boldsymbol { B }} \\
(\mathrm{N} / \mathrm{mm}) \\
\end{array}$ & $\begin{array}{c}\boldsymbol{I S B} \\
(\mathrm{N} / \mathrm{mm}) \\
\end{array}$ & $\begin{array}{c}\boldsymbol{A S T B} \\
(\mathrm{N} / \mathrm{mm}) \\
\end{array}$ & $\begin{array}{c}\boldsymbol{F S T B} \\
(\mathrm{N} / \mathrm{mm}) \\
\end{array}$ & $\begin{array}{c}\boldsymbol{I S B} \\
(\mathrm{N} / \mathrm{mm})\end{array}$ \\
\hline$A S T B$ & 4306 & I & -10784 & 35200 & -76200 & 50700 \\
\hline FSTB & I & I & I & -76200 & 175000 & 133000 \\
\hline$I S B$ & -10784 & / & 32914 & 50700 & -133000 & 141000 \\
\hline $\begin{array}{l}\text { M/E B } \\
\text { No.1 }\end{array}$ & 24297 & / & -109205 & -30700 & 109000 & -224000 \\
\hline $\begin{array}{l}\text { M/E B } \\
\text { No. } 2\end{array}$ & -17974 & / & 87833 & 21500 & -76400 & 170000 \\
\hline $\begin{array}{l}\text { M/E B } \\
\text { No.3 }\end{array}$ & 189 & / & -926 & -640 & 2270 & -5050 \\
\hline $\begin{array}{l}\text { M/E B } \\
\text { No.4 }\end{array}$ & -42 & / & 205 & 171 & -606 & 1350 \\
\hline $\begin{array}{l}\text { M/E B } \\
\text { No.5 }\end{array}$ & 8 & / & -43 & -42.6 & 151 & -337 \\
\hline $\begin{array}{l}\text { M/E B } \\
\text { No.6 }\end{array}$ & -1 & / & 6 & 7.11 & -25.2 & 56.1 \\
\hline
\end{tabular}




\section{Shafting Vibration Test and Analysis}

Marine shafting vibration is an important index for analyzing the operating condition of marine shafting. The calculation documents of marine shafting torsional vibration and longitudinal vibration will be proceed during large ship designing, which are used to predict the performances of shafting vibration in theory. And sometimes the transversal vibration is required to calculate the whirl vibration. Then the performances and trend of the marine shafting vibration can be gotten by analyzing the calculated data. In addition, real situation of the marine shafting needs to be validated by test data of shafting vibration. So two set of instruments, ANZT and TLC-Iare applied to measure the real data of marine shafting torsional vibration and longitudinal vibration respectively. The amplitude-speed curves of torsional vibration are showed in Figure 3. And Figure 3(a) represents the performance of the shafting with double stern-tube bearings. Figure 3 (b) represents the performance of the shafting with a single stern-tube bearing. The amplitude-speed curves of longitudinal vibration are shown in Figure 4 and Figure 5.
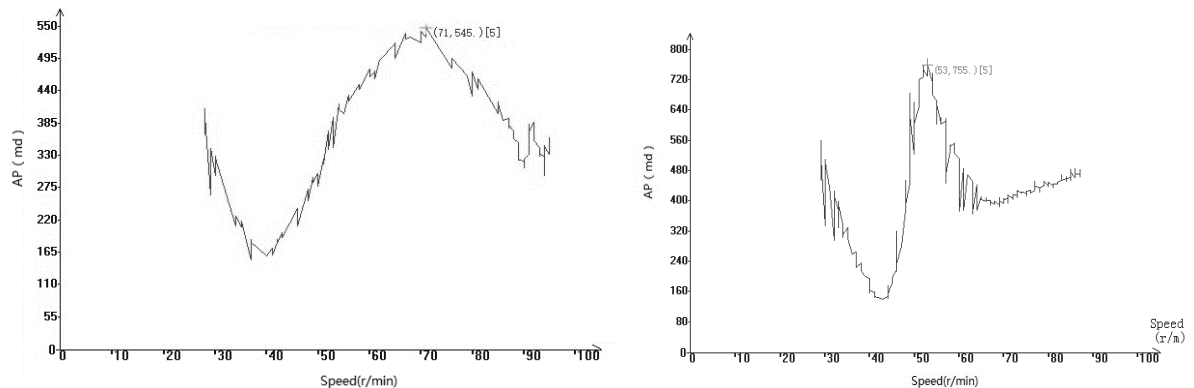

(a) Shafting with double stern-tube bearing

(b) Shafting with a single stern-tube bearing Figure 3 Amplitude-Speed Curve of Torsional Vibration

From Figure 3, it can be seen the resonance speed of the torsional vibration of shafting with a single stern-tube bearing is 53r/min, and for the shafting with double stern-tube bearings the resonance speed is $70.8 \mathrm{r} / \mathrm{min}$. By analyzing and comparing the shafting vibration calculation, the figures in Table 4 can be sorted out. In Table 4, the calculated resonance frequency of torsional vibration matches with the measured one for the two kinds of shafting and the relative errors are both less than 5\%, which is in the permissible range of CCS. So it is reasonable to use these data for the two kinds of ship shafting vibration characteristic analysis in this paper. Through analyzing the data, some conclusions can be drawn. At first, there is a difference in the resonance frequency between the shafting with a single stern-tube bearing and the shafting with double stern-tube bearings. Secondly, for the shafting with a single stern-tube bearing, the resonance speed is in the 1st node and 5th order. And for the shafting with double stern-tube bearings, the resonance speed is in the $2 \mathrm{rd}$ node and 5th order. At last, there is a restricted speed range in the shafting with a single stern-tube bearing, and there is not a restricted speed range in the shafting with double stern-tube bearing.

Table 4 Resonance Speed and Frequency (Torsional Vibration)

\begin{tabular}{lcc}
\hline Items & $\begin{array}{c}\text { Ship with Single } \\
\text { Stern-tube Bearing }\end{array}$ & $\begin{array}{c}\text { Ship with Double } \\
\text { Stern-tube Bearing }\end{array}$ \\
\hline Node & 1 & 2 \\
Resonance Order & 5 & 5 \\
Resonance Speed(r/min) & 53 & 70.8 \\
Frequency Measured (1/min) & 265.0 & 354.0 \\
Frequency calculated (1/min) & 260.4 & 349.9 \\
Relative Error (\%) & 1.77 & 1.17 \\
Angular deflection (deg) & 0.755 & 0.545 \\
\hline
\end{tabular}

The performances of the shafting longitudinal vibration of the ships are shown in the Figure 4, Figure 5 and Table 5. There are two points about the performances need to be cleared. The first one is there is little difference in the resonance frequency of the longitudinal vibration between the two shafting. The second one is that the amplitude of the longitudinal vibration in shafting with a single 
stern-tube bearing is greater than that of shafting with double stern-tube bearing, the magnitude difference is one order and there are two peaks in single stern-tube bearing. The following can be further drawn: the longitudinal vibration reduction device can affect the shafting longitudinal vibration intensity directly; however the influence of different type of stern bearing cannot be ignored also.

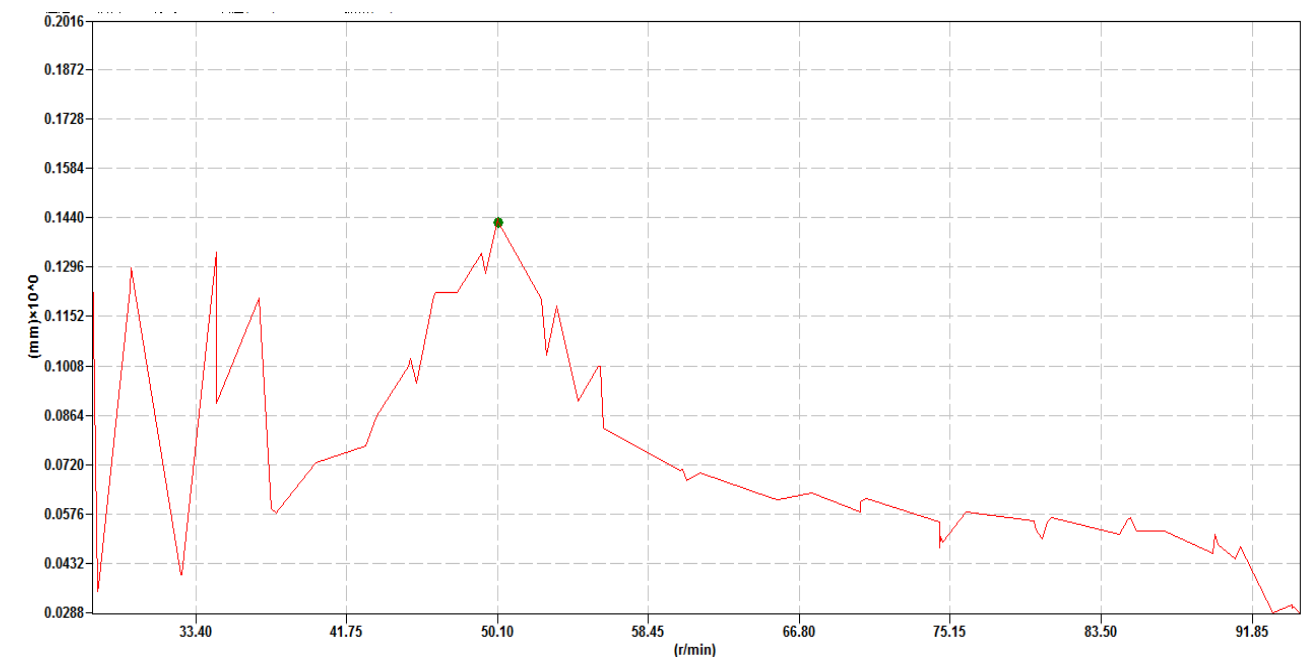

Figure 4 Amplitude-Speed Curve of Longitudinal Vibration (Double Stern-tube Bearing)

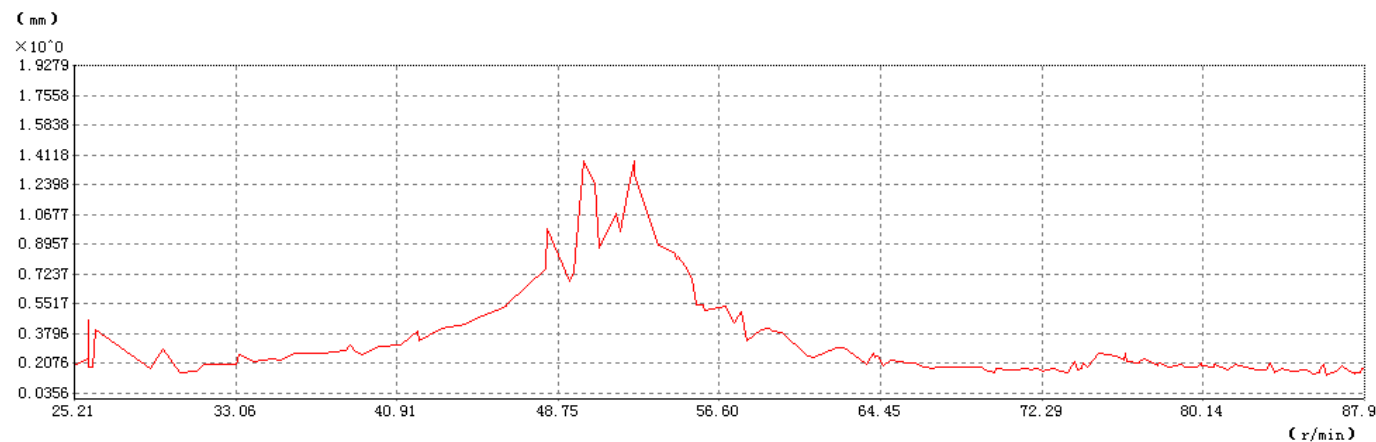

Figure 5 Amplitude-Speed Curve of Longitudinal Vibration (Single Stern-tube Bearing) Table 5 Resonance speed and frequency (longitudinal vibration)

\begin{tabular}{|l|c|c|c|}
\hline \multirow{2}{*}{ Items } & \multicolumn{2}{|c|}{$\begin{array}{c}\text { Ship with Single Stern-tube } \\
\text { Bearing(Hz) }\end{array}$} & $\begin{array}{c}\text { Ship with Double } \\
\text { Stern-tube Bearing(Hz) }\end{array}$ \\
\cline { 2 - 3 } & Case1 & Case2 & \\
\hline Node & 2 & 2 & 2 \\
\hline Resonance Order & 5 & 5 & 5 \\
\hline Resonance Speed(r/min) & 50.02 & 52.44 & 50.08 \\
\hline Frequency Measured $(1 / \mathrm{min})$ & 250.1 & 262.2 & 250.4 \\
\hline translation deflection $(\mathrm{mm})$ & 1.3762 & 1.3724 & 0.1431 \\
\hline
\end{tabular}

\section{Summary}

For large ships, the influence of fore stern bearing to the load of aft stern tube bearing and middle bearing is obvious, which is helpful to improve the dynamic mechanics characteristics of shaft system, and thus reduces the vibration effect to shafting system. The resonance speed of shaft torsional vibration changes with the change of the mechanics characteristics. The improvement of shafting mechanics characteristics can also make the shafting longitudinal vibration improved obviously.

\section{Acknowledgement}

The present research is partly funded by Public Projects of Zhejiang Province (2103C31050), the S\&T Plan Projects of Zhoushan City (2014C31050), the S\&T Plan Projects of Zhoushan City 
(2013C41011), the Educational Projects of Zhejiang Province (Y201121736), and the Natural Science Foundation of Zhejiang Province (LY16E090003).

\section{References}

[1] Xiao Zhijian. Analysis and solution of the torsional vibration by FEM[J]. Journal of Guangdong Shipping, 2006,(3):34-37.

[2] Zhang Ye. The Study of Torsional Vibration Calculation Method of 6S50MC-C Marine Diesel Engine Shafting [D].Dalian: Dalian Maritime University, 2009.

[3] Zhao $\mathrm{Wu}$. Investigations on detection model of large scale rotation shaft torsional vibration in precision heavy machinery [J]. International Asia Conference on Informatics in Control, Automation and Robotics,2009:459-463.

[4] Qin Chunyun, Yang Zhirong, Rao Zhushi, Ta Na. Study on Suppression of the Longitudinal Vibration of Ship's Propulsion Shafting System [J]. Noise and Vibration Control,2013, 33(3):147-153.

[5] Li Liangwei, Zhao Yao, Lu Po, Li Tian. Optimization of Dynamic Absorber Parameters for Reducing Axial Vibration of Ship Shafting [J]. Shipbuilding of China,2010, 51(2):139-148.

[6] Zhu Hanhua, Yan Xinping, Yan Xinping, et al. Research on Impact Response Relationship Between the Rotating Speed and Lateral Vibration [J]. Journal of Wuhan University of Technology,2008,32(6):983-986.

[7] Zhang Xiaodong. Influence of Equivalent Supporting Point Location in Stern Bearing on Shaft Whirling Vibration[J]. Ship \& Ocean Engineering,2012,41(6):46-49.

[8] Wang Lei, Xie Junchao, Zhou Ruiping. Analysis of the shafting transversal vibration in large ship[J]. Jiangsu Ship, 2010, 27(1):14-17.

[9] Pan J, Farag N, Lin T, Juniper R. Propeller induced structural vibration though the thrust bearing[C]//Innovation in Acoustics and Vibration Annual Conference of the Australian Acoustical Society. Adelaide, Australia, November 13 .15. 2002, 390 -399.

[10] Li Liangwei, Zhao Yao, Zhang Ganbo. Research of Axial Coupling Vibration Characteristic of Marine Shaft Test Bed [C]. Conference Proceeding of China Steel Construction Society Ocean Steel Structure Branch Association: 2010 Academic Conference . Luoyang, China, 2010:276-284.

[11] X. F. Wen, X.D. Wang, Q. Yuan. A Study on Technology of Ship Shafting Torsional Vibration[C].International Conference on Manufacturing and Engineering, April 9-11,1423-1428, Guilin, 2011.

[12]X.F. Wen, Q. Yuan, J.S. Lu, et al. Analysis of Propulsion Shafting Torsional Vibration of Vessels with Double Engines and Double Propellers[C]. 3rd International Conference on Manufacturing and Engineering, March 27-29,1423-1428,Xiamen, 2012. 